\title{
Erratum: Membrane-dependent signal integration by the Ras activator Son of sevenless
}

Jodi Gureasko, William J Galush, Sean Boykevisch, Holger Sondermann, Dafna Bar-Sagi, Jay T Groves \& John Kuriyan Nat. Struct. Mol. Biol. 15, 452-461 (2008); published online 4 May; corrected after print 15 May 2008

In the version of this article initially published, the concentration units reported in Figure $7 \mathrm{~b}, \mathrm{c}$ should be nM, not nm. The green data series in Figure $7 \mathrm{~b}$ should be labeled "SOS ${ }^{\text {cat". }}$ The corrected figure panels are shown below:

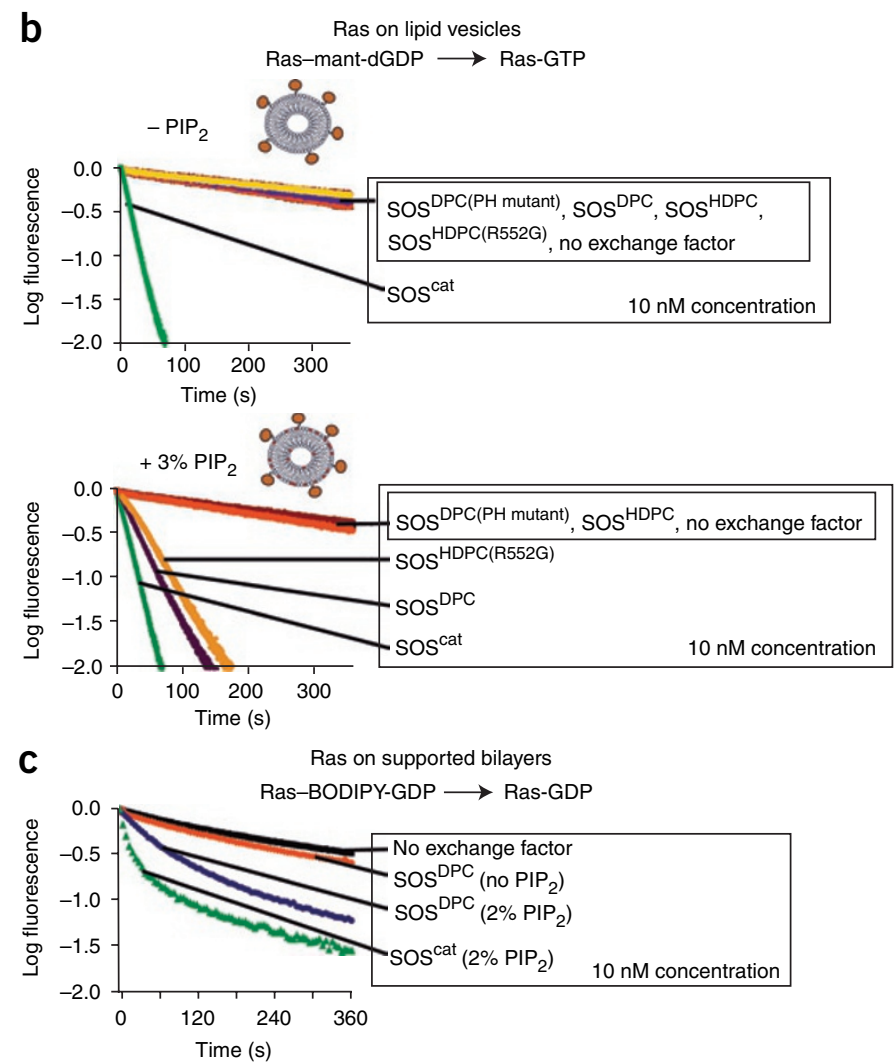

In addition, on page 452 of the article, the affiliation address for William J. Galush and Jay T. Groves was incorrect. Their correct address is Department of Chemistry, University of California, Berkeley, California 94720, USA. Finally, the last sentence of the Acknowledgments listed incorrect funding information. The last sentence should read, "J.T.G. and W.J.G. are supported by Chemical Sciences, Geosciences and Biosciences Division, Office of Basic Energy Sciences of the US Department of Energy under Contract No. DE_AC03-76SF00098, and D.B.-S. by NIH GM078266.” These errors have been corrected in the HTML and PDF versions of the article.

\section{Corrigendum: The refined structure of nascent HDL reveals} a key functional domain for particle maturation and dysfunction

Zhiping Wu, Matthew A Wagner, Lemin Zheng, John S Parks, Jacinto M Shy III, Jonathan D Smith, Valentin Gogonea \& Stanley L Hazen Nat. Struct. Mol. Biol. 14, 861-868 (2007); published online 5 August 2007; corrected after print 22 May 2008

In the version of this article initially published, the legend text for Figure $2 \mathrm{c}$ was incorrect, with the terms "clockwise" and "counterclockwise" swapped. The error has been corrected in the PDF and HTML versions of the article. 